\section{Acknowledging rural context, local and generalist care}

Sur and Loh are to be commended for their article on the management of a man disclosing crack cocaine use at a rural clinic. ${ }^{1}$ However, they do not elaborate on the rural context or acknowledge their recommendations' potential limitations in rural Canada.

Their guidance focuses on taking a history, ordering a battery of tests and referring to specialized services outside the primary care clinic. This does not recognize shortages of rural addiction services or the potential for skilled generalists to offer excellent care at the very clinic where the patient presented. ${ }^{2,3}$ The authors offer little guidance for how a generalist might care for the patient comprehensively, locally and realistically.

Serious drug misuse can be viewed as a disastrous form of "self-treatment." Our task as caregivers might include identifying and treating underlying mental health disorders and trauma within the comprehensive family practice clinic. ${ }^{4}$ A discussion of these issues might seem a good starting point.

The article concludes that the "physician ... subsequently referred the patient to a harm-reduction clinic for education and counselling and ongoing access to support services and the local safe inhalation kit distribution program." These services exist in some rural settings, but they are not the rural norm. The authors unfortunately identify decontextualized guidelines, urban evidence and largely nonexistent rural services.

Patients living in rural areas typically receive excellent care through a generalist model. Although some may need to be referred to specialized urban centres, rural patients and clinicians need robust strategies and guidance for treatment close to home. ${ }^{5}$
Aaron M. Orkin MD MSc

Dalla Lana School of Public Health,

Toronto, Ont.

\section{Len Kelly MD}

Anishnaabe Bimaadiziwin Research Program, Sioux Lookout Meno Ya Win Health Centre, Sioux Lookout, Ont

\section{References}

1. Sur AHW, Loh L. A 38-year-old man who uses crack cocaine. CMAJ 2015;187:1383-4

2. Sibley LM, Weiner JP. An evaluation of access to health care services along the rural-urban continuum in Canada. BMC Health Serv Res 2011; Jan. 31: 11:20 DOI: 10.1186/1472-6963-11-20.

3. Canadian Mental Health Association. Rural and northern community issues in mental health; 2009. Available: https://ontario.cmha.ca/public_policy/ rural-and-northern-community-issues-in-mentalhealth/\#.Vh08-YfdDrM (accessed 2015 Oct. 13).

4. Mate G. In the realm of the hungry ghost. Mississauga, Ont.: Knopf; 2008

5. Jiwa A, Kelly L, St.Pierre-Hansen N. Aboriginal community-based addictions treatment - a literature review. Can Fam Physician 2008;54:1000-1000.e7.

CMAJ 2016. DOI:10.1503/cmaj.1150083

\section{The authors respond}

We thank Orkin and Kelly for their letter about the stated rural context in our recent Decisions piece. ${ }^{1}$

One concern they expressed is that our piece focuses too heavily on "taking a history, ordering a battery of tests and referring to specialized services." We submit that this is the primary purpose of the case study, in line with CMAJ's expectations for its Decisions articles, which asks authors to describe "key issues that should be addressed in the first appointment [and] may include examination, investigation, treatment, harm reduction, follow-up, or referrals."2

Related to this, is the other concern Orkin and Kelly expressed - that the guidance does not sufficiently account for limitations of rural primary care practice. The primary purpose of this case study was to review clinical decision-making rather than provide a broad review of care disparities that may exist between rural and urban settings. Understanding that, we can also disclose that this fictional encounter was originally written with a suburban setting in a major metropolitan area in mind. The change to a rural setting occurred in response to suggestions made during the review process.

We agree that care is highly contextual and thank Orkin and Kelly for the kind reminder. In this instance, a seemingly simple change (literally altering a single word) resulted in presenting a case in a vastly different locale with challenges to the feasibility and appropriateness of proposed guidance. Ironically, while we were preparing this Decisions case, our supporting research uncovered substantial disparities in access to harm reduction services between urban and rural settings. As already mentioned, our ability to address these in detail was limited by format and space restrictions. However, we agree that differential access to various support services would impact the nature of care provided in different settings.

Further work from Orkin and Kelly would be welcome, with perhaps a specific focus on management challenges around crack cocaine use in rural settings. We again acknowledge that the original context underpinning our Decisions piece was a nonrural setting.

\section{Lawrence C. Loh MD MPH}

Dalla Lana School of Public Health, University of Toronto, Toronto, Ont. Amy H.W. Sur MD

McMaster University, Hamilton, Ont.

\section{References}

1. Orkin AM, Kelly L. Acknowledging rural context, local and generalist care [letter]. CMAJ 2016:188;286.

2. CMAJ Instructions for authors - decisions. Available: www.cmaj.ca/site/authors/decisions-author -instructions.pdf (accessed 2015 Dec. 4).

CMAJ 2016. DOI:10.1503/cmaj.11500884

\section{Letters to the editor}

In submitting a letter, you automatically consent to having it appear online/in print. All letters accepted for print will be edited for space and style. See www.cmaj.ca for full versions and competing interests. 